\title{
Diffusion Weighted Magnetic Resonance Imaging in Diffuse and Focal Vertebral Bone Marrow Lesions Using Apparent Diffusion Coefficient (ADC) Mapping as a Quantitative Assessment Tool
}

\author{
NARDINE N. HELMY, M.Sc.*; MOHAMED A. HASSAAN, M.D.*; AMR Y. SAKR, M.D.** and \\ MOHAMED T. ALI, M.D.* \\ The Departments of Radiology* and Radiotherapy**, Faculty of Medicine, Cairo University
}

\begin{abstract}
Background: Routine magnetic resonance imaging MRI is highly sensitive in detecting bone marrow alterations; however, it is of limited specificity in the evaluation of the causes of these alterations. Diffusion Weighted Imaging (DWI) is an imaging technique which probes the structure of a biologic tissue. The contrast achieved with this technique together with measurement of the apparent diffusion coefficient ADC values are useful complementary MRI tools and can be used for non-invasive tissue characterization and therefore reaching a more specific diagnosis.
\end{abstract}

Aim of Work: The aim of this study is to determine the value of both qualitative and quantitative assessment of DWI in differentiation between different vertebral lesions and to determine cut off $\mathrm{ADC}$ value between benign and malignant lesions.

Patients and Methods: This is a prospective study carried out in Radio-Diagnosis Department, Faculty of Medicine, Cairo University between August 2014 and February 2016 for patients diagnosed with or suspected to have vertebral lesion of any etiology. A total number of 40 patients ( 22 males and 18 females) with age range 2-88 (average 49).

The MRI sequences obtained were sagittal T1WI, T2WI, STIR and axial T1WI, T2WI \& DWI ( \pm post contrast images in some patients). Bone marrow signal intensity was qualitatively analyzed by visually comparing its signal intensity with the signal intensity of the intervertebral disc, fat and muscle tissue on T1-weighted images. Hyperintense lesions on the DWI were identified and ADC values were automatically calculated using the software provided by the MR scanner manufacturer (Diffusion Calculation: Philips Medical Systems) and the $\mathrm{ADC}$ quantitative parameter was expressed in: $10^{-3} \mathrm{~mm} / \mathrm{s}$.

Results: Our study included 40 patients who were diagnosed with or suspected to have vertebral lesion of any etiology. Qualitative evaluation of the lesion contrast in diffusion-weighted MRI of the vertebral column has been shown to be valuable for the differentiation of lesion etiology;

Correspondence to: Dr. Nardine N. Helmy, The Department of Radiology, Faculty of Medicine, Cairo University however, visual assessment of high signal intensity was not specific for malignancy.

On the other hand the quantitative assessment by measuring the ADC value was able to distinguish benign from malignant high signal intensity on DWI.

In our study, infiltrated neoplastic marrow as well as hypercellular red marrow had higher ADC values than normal marrow while inflammatory lesions and hemangiomas had the highest $\mathrm{ADC}$ values.

Conclusion: Diffusion weighted MRI is a reliable tool in characterization of different vertebral bone marrow abnormalities. The routine MRI protocol of spine examinations could be modified to include DWI as a cost effective substitute for the gadolinium enhanced scan especially in patients with contraindication for contrast administration.

Key Words: DWI - Vertebral lesions - Bone marrow - ADC - Malignant lesions.

\section{Introduction}

MAGNETIC Resonance Imaging (MRI) is the mainstay of diagnosis, staging and follow-up of much musculoskeletal pathology. Diffusionweighted magnetic resonance imaging (DWI) is a recent addition to the MR sequences conventionally employed [1]

DWI provides qualitative and quantitative functional information concerning the microscopic movements of water at the cellular level. The signal intensity of DWI relies on the stochastic Brownian motion, or self diffusion of water molecules at a microscopic level within tissues. Extracellular water has more freedom, or is less impeded in its motion, in comparison to intracellular water molecules, which are limited in their motion by intracellular organelles, macromolecules and cell membranes. Areas with higher cellularity (and therefore more intracellular components and cell membranes) 
will demonstrate impeded molecular water mobility [1].

Diffusion-weighted MRI has been used successfully in the Central Nervous System (CNS), especially in the diagnosis of acute stroke, but also in distinguishing different components of brain tumors. Diffusion measurements of tumors outside the brain have also been reported [2].

DWI is a fast MRI sequence, which offers without any contrast media injection, assessment of various types of spine vertebral and discal lesions [3].

In cases of bone marrow infection; while benign in nature, osteomyelitis can cause hyperintensity on DWI which may mimic malignancy [4] .

In diffusion-weighted images of the spine, malignant lesions appear predominantly hyperintense. Hypointense signal of malignant vertebral lesions, may be explained either by lesions irradiated before imaging or by sclerotic metastases with very low water content [5].

DWI did not show high signal intensity at the site of endplate abnormalities in patients with degenerative changes [6]

Diffusion weighted imaging is also useful in post-treatment follow-up of bone marrow neoplastic lesions. When bone marrow disease is treated successfully, the tumour cell death results in increased water diffusivity manifested as increased ADC values [1]

Aim of the work: The aim of this study is to determine the value of both qualitative and quantitative assessment of DWI in differentiation between different vertebral lesions and to determine cut off ADC value between benign and malignant lesions.

\section{Patients and Methods}

This is a prospective study carried out in RadioDiagnosis Department, Faculty of Medicine, Cairo University between August 2014 and February 2016 for patients diagnosed with or suspected to have vertebral lesion of any etiology. Informed consent was obtained for this ethics committee approved study.

A total number of 40 patients ( 22 males and 18 females) with age range 2-88 (average 49).

\section{Inclusion criteria:}

- Patients diagnosed with vertebral lesion or vertebral bone marrow abnormality.

- Patients suspected to have vertebral lesion.

Exclusion criteria:

- Patients with pacemaker.

- Patients with claustrophobia.

Patients were subjected to the following:

1- Clinical assessment: Short medical history was taken from out patients, however; more detailed clinical and laboratory data were obtained from in-patients.

\section{2- Radiological investigations:}

A- MRI examination: All patients were subjected to MRI examination. Some patients received IV contrast "gadolinium D.T.P.A".

B- Plain X-ray, CT, or bone scan were done for some of the patients.

C- Pathological examination results were available in some cases form which biopsy was taken during our study.

MR imaging technique:

- Imaging was performed using a standard 1.5 Tesla unit (Intera and Achieva, Philips).

- A sense spine coil was used.

A- Routine MRI sequences of spine:

- Sagittal T1WI, T2WI \& STIR.

- Axial T1WI \& T2WI.

- Contrast enhanced images (in some patients) after manual intravenous administration of $0.1 \mathrm{mmol} / \mathrm{kg}$ of gadolinium-DTPA.

B- DWI of spine:

DWI was performed with free breathing and inversion recovery single-shot spin-echo echoplanar sequences (TR/TE, 9000/68; number of slices, 12; slice thickness, $5 \mathrm{~mm}$; gap, $0 \mathrm{~mm}$; flip angle, $90^{\circ}$; FOV, $300 \mathrm{~mm}$ ). We applied 3 diffusionsensitizing gradients with $b$-values of 0,50 and $800 \mathrm{~s} / \mathrm{mm}^{2}$. The total imaging time was $6: 09 \mathrm{~min}$.

Image analysis:

All images were loaded to a workstation (Philips Medical Systems). Bone marrow evaluation and image interpretation were performed.

\section{A- Qualitative analysis:}

Bone marrow signal intensity was qualitatively analyzed by visually comparing its signal intensity 
with the signal intensity of the non-degenerated intervertebral disc, subcutaneous fat and muscle tissue depicted on T1-weighted images. For MRI interpretation, we used previously established diagnostic criteria for vertebral bone marrow evaluation.

\section{B- Quantitative analysis:}

The radiologist quantitatively evaluated the bone marrow signal intensity by performing measurements in Regions of Interest (ROI). Hyperintense lesions on the DWI (with a high $b$-value " $b$ $800 "$ ) which correspond to the lesions with abnormal signal intensity changes on the T1 \& T2 weighted MR images were identified and the ROI was manually drawn within the confines of the hyperintensity.

The ROI was lesion-size-dependent in localized discrete lesions, but in diffuse vertebral marrow lesions it was drawn as large as possible placed in the antrocentral aspect of vertebral body to avoid vertebral end plate degenerative changes and basivertebral vein plexus.

In addition the ADC value of normal/normal appearing vertebral bodies were measured by placing ROI at the center of the vertebral bodies.

The regions of interest varied between 5 and $15 \mathrm{~mm}$ in diameter. In each patient at least $3 \mathrm{ROI}$ were applied.

ADC values were automatically calculated using the software provided by the MR scanner manufacturer (Diffusion Calculation: Philips Medical Systems) and the ADC quantitative parameter was expressed in: $10 \mathrm{~mm} / \mathrm{s}$. The average ADC value of the three regions of interest of each patient was calculated and recorded. The final diagnosis which was made on the basis of biopsy results or results of clinical and radiologic follow-up was used as the "gold standard" to classify the vertebral marrow lesions.

\section{Results}

A total number of 40 patients ( 22 males and 18 females) with age range 2-88 (average 49) diagnosed with or suspected to have vertebral lesion of any etiology were radiologically evaluated.

The vertebral bone marrow abnormalities classification:

The patients included in the study were 21 of benign nature and 19 malignant vertebral marrow infiltrative lesions (Table 1). This diagnosis is based on clinical, radiological and histo-pathological data. The 21 patients with benign marrow lesions included 9 patients with inflammatory/infectious spondylitis or spondylodiscitis, 4 patients with benign neoplastic marrow lesions, 3 patients with diffuse yellow to red marrow reconversion and 5 patients with degenerative marrow changes.

On the other hand the 19 patients with established malignant multifocal or infiltrative vertebral marrow lesions included metastatic lesions $(\mathrm{n}=17)$ lymphomatous infiltration $(\mathrm{n}=1)$ and multiple myeloma $(n=1)$.

Table (1): Classification of the vertebral bone marrow abnormalities.

\begin{tabular}{lc}
\hline Group & No. of patients \\
\hline Inflammatory & 9 \\
Benign neoplastic lesion & 4 \\
Malignant neoplastic lesion & 19 \\
Red marrow & 3 \\
Degenerative & 5 \\
\hline
\end{tabular}

Inflammatory lesions:

On DWIs, all lesions in the inflammatory group revealed high signal intensity. The mean ADC value of pyogenic spondylodiscitis wass high (mean; $1.454 \times 10^{-9} \mathrm{~mm} / \mathrm{s}, \mathrm{SD} \pm 0.16 \times 10^{-3} \mathrm{~mm}^{2} / \mathrm{s}$ ) while TB spondylodiscitis were of lower ADC valueş (mean; $1.191 \times 10^{-3} \mathrm{~mm}^{2} / \mathrm{s}, \mathrm{SD} \pm 0.29 \times 10$ $\mathrm{mm}^{2} / \mathrm{s}$ ) (Table 2).

Table (2): DWI signal and ADC values in inflammatory lesions.

\begin{tabular}{lccc}
\hline \multirow{2}{*}{ Diagnosis } & $\begin{array}{c}\text { DWI } \\
\text { signal }\end{array}$ & \multicolumn{2}{c}{$\begin{array}{c}\mathrm{ADC}_{3} \text { value } \\
\left(\mathrm{X} \mathrm{10}^{2} \mathrm{~mm}^{2} / \mathrm{s}\right)\end{array}$} \\
\cline { 3 - 5 } & & Range & Mean $\pm \mathrm{SD}$ \\
\hline Pyogenic spondylodiscitis & High & $1.369-1.690$ & $1.454 \pm 0.16$ \\
TB spondylodiscitis & High & $0.902-1.564$ & $1.191 \pm 0.29$ \\
\hline
\end{tabular}

Benign Neoplastic lesions:

A total of four cases with benign neoplastic vertebral lesions were found: Three cases with hemangioma and one case with osteoblastoma.

On DWIs, hemangiomas revealed low signal intensity while the osteoblastoma revealed high signal intensity. The mean ADC value of the hemangioma was high (mean; $1.406 \times 10^{-3} \mathrm{~mm} / \mathrm{s}$, $\mathrm{SD} \pm 0.13 \times 10^{-3} \mathrm{~mm} / \mathrm{s}$ ) while osteoblastoma was of lower ADC value $\left(0.818 \times 10^{-3} \mathrm{~mm}^{2} / \mathrm{s}\right)$ (Table 3). 
Table (3): DWI signal and ADC values in benign neoplastic lesions.

\begin{tabular}{|c|c|c|c|}
\hline \multirow[t]{2}{*}{ Diagnosis } & \multirow{2}{*}{$\begin{array}{l}\text { DWI } \\
\text { signal }\end{array}$} & \multicolumn{2}{|c|}{$\begin{array}{c}\mathrm{ADC}_{-3} \text { value } \\
\left({\mathrm{X} 10^{2}}^{\mathrm{mm}} / \mathrm{s}\right)\end{array}$} \\
\hline & & Range & Mean \pm SD \\
\hline Hemangioma & Low & $1.254-1.512$ & $1.406 \pm 0.13$ \\
\hline Osteoblastoma & High & \multicolumn{2}{|c|}{0.818} \\
\hline
\end{tabular}

\section{Malignant Neoplastic lesions:}

A total of nineteen cases with malignant vertebral lesions were found: Seventeen patients with metastatic lesions, a case of lymphoma and a case of multiple myeloma. The case of lymphoma and one of the patients with metastasis were presenting for follow-up after receiving therapy.

On DWIs, eighteen malignant lesions revealed high signal intensity while the case of multiple myeloma revealed low signal intensity. The mean ADC value of the non treated malignant lesions was (mean; $0.982 \times 10^{-3} \mathrm{~mm} / \mathrm{s}, \mathrm{SD} \pm 0.17 \times 10^{-3}$ $\mathrm{mm}^{2} / \mathrm{s}$ ) while the two lesions under therapy were of higher ADC values $(1.612 \& 1.483$ X 10 $\mathrm{mm}^{2} / \mathrm{s}$ ) (Table 4).

Table (4): DWI signal and ADC values in malignant neoplastic lesions.

\begin{tabular}{|c|c|c|c|c|}
\hline \multirow[t]{2}{*}{ Diagnosis } & \multirow{2}{*}{$\begin{array}{l}\text { DWI } \\
\text { signal }\end{array}$} & \multirow{2}{*}{ No. } & $\begin{array}{c}\mathrm{ADC}_{-3} \text { value } \\
\left({\mathrm{X} 10^{-}}^{\mathrm{mm}} / \mathrm{s}\right)\end{array}$ & \multirow{2}{*}{ No. } \\
\hline & & & Range Mean \pm SD & \\
\hline \multicolumn{5}{|l|}{ Metastasis: } \\
\hline Pretherapy. & High & 160 & $0.624-1.237 \quad 0.982 \pm 0.17$ & 16 \\
\hline Post therapy. & High & 1 & 1.612 & 1 \\
\hline Multiple myeloma. & Low & 1 & 0.975 & 1 \\
\hline $\begin{array}{l}\text { Lymphoma: } \\
\text { Post therapy. }\end{array}$ & High & 1 & 1.483 & 1 \\
\hline
\end{tabular}

Red marrow (persistent/reconversion):

On DWIs, one case was of high signal intensity while the other two cases were of low signal intensity $_{3}$ Thę mean ADC value was (mean; $0.613 \mathrm{X}$ $10^{-3} \mathrm{~mm}^{2} / \mathrm{s}, \mathrm{SD} \pm 0.08 \times 10^{-3} \mathrm{~mm}^{2} / \mathrm{s}$ ) (Table 5).

Table (5): DWI signal and ADC values in the red marrow group.

\begin{tabular}{lcccc}
\hline \multirow{2}{*}{ Diagnosis } & \multirow{2}{*}{$\begin{array}{c}\text { DWI } \\
\text { signal }\end{array}$} & No. & \multicolumn{2}{c}{\begin{tabular}{c}
$\mathrm{ADC}_{3}$ valuę \\
\cline { 3 - 5 }
\end{tabular}} \\
\cline { 3 - 5 } & & Range 10 & Mm $/ \mathrm{s})$ \\
\hline Red marrow & High & 1 & $0.544-0.711$ & $0.613 \pm 0.08$ \\
& Low & 2 & & \\
\hline
\end{tabular}

Degenerative changes of the bone marrow:

On DWIs, degenerative lesions revealed low signal intensity. The mean ADC value was (mean; $\left.0.569 \times 10^{-3} \mathrm{~mm}^{2} / \mathrm{s}, \mathrm{SD} \pm 0.06 \times 10^{-3} \mathrm{~mm}^{2} / \mathrm{s}\right)$ (Table 6).

Table (6): DWI signal and ADC values in the degenerative group.

\begin{tabular}{|c|c|c|c|}
\hline \multirow{2}{*}{ Diagnosis } & \multirow{2}{*}{$\begin{array}{l}\text { DWI } \\
\text { signal }\end{array}$} & \multicolumn{2}{|c|}{$\begin{array}{c}\mathrm{ADC}_{3} \text { valuę } \\
\left(\mathrm{X} 10^{\mathrm{mm}} / \mathrm{s}\right)\end{array}$} \\
\hline & & Range & Mean \pm SD \\
\hline MODIC I & Low & $0.525-0.664$ & $0.569 \pm 0.06$ \\
\hline MODIC II & Low & & \\
\hline
\end{tabular}

Summary of ADC values of the different groups:

Table (7): DWI signal and ADC values of the different groups.

\begin{tabular}{lccc}
\hline \multirow{2}{*}{ Diagnosis } & \multirow{2}{c}{$\begin{array}{c}\mathrm{ADC}_{2} \text { value } \\
\end{array}$} & $\begin{array}{c}\text { DWI } \\
\text { signal }\end{array}$ & \multicolumn{2}{c}{ (X 1 0 } & mm $/ \mathrm{s})$ \\
\cline { 3 - 4 } & & Range & Mean $\pm \mathrm{SD}$ \\
\hline Pyogenic spondylodiscitis & High & $1.369-1.690$ & $1.454 \pm 0.16$ \\
TB spondylodiscitis & High & $0.902-1.564$ & $1.191 \pm 0.29$ \\
Hemangioma & Low & $1.254-1.512$ & $1.406 \pm 0.13$ \\
Malignant & High & $0.624-1.237$ & $0.982 \pm 0.17$ \\
Red marrow & High & $0.544-0.711$ & $0.613 \pm 0.08$ \\
& Low & & \\
Degenerative changes & Low & $0.525-0.664$ & $0.569 \pm 0.06$ \\
\hline
\end{tabular}

The ADC values recorded from the automatically created ADC maps (Table 7) differed significantly ( $p$-value $<0.001$, highly significant) between malignant (mean, $0.982 \times 10^{-3} \mathrm{~mm}^{2} / \mathrm{s} ; \mathrm{SD} \pm 0.17$ $\mathrm{X} 10 \mathrm{~mm} / \mathrm{s}$ ) and the following benign marrow entities; inflammatory pyogenic marrow lesions (mezan, $1.454 \pm 0.322 \times 10 \mathrm{~mm} / \mathrm{s}$; SD $\pm 0.16 \mathrm{X}$ $\left.10^{-3} \mathrm{~mm} / \mathrm{s}\right)$ and the dęgenerative marrow changes (mean, $0.569 \times 10^{-5} \mathrm{~mm}^{2} / \mathrm{s}$; SD $\pm 0.06 \times 10$ $\left.\mathrm{mm}^{2} / \mathrm{s}\right)$. ADC values of malignant lesions also differed significantly ( $p$-value 0.002 , significant) from the hemangiomas (mean, $1.406 \pm 0.13 \times 10$ $\left.\mathrm{mm}^{2} / \mathrm{s} ; \mathrm{SD} \pm 0.16 \times 10^{-3} \mathrm{~mm}^{2} / \mathrm{s}\right)$.

There was an overlap between the ADC values of malignant lesions and TB spondylodiscitis (mean, $1.191 \times 10^{-3} \mathrm{~mm}^{2} / \mathrm{s}$; SD $\pm 0.29 \times 10$ $\mathrm{mm}^{2} / \mathrm{s}$ ), yet with a statistically significant difference ( $p$-value 0.034 , significant) in their ADC values. An overlap between the ADC values of malignant lesions and the red marrow (mean, $0.613 \times 10^{-3}$ $\mathrm{mm}^{2} / \mathrm{s} ; \mathrm{SD} \pm 0.08 \times 10^{-3} \mathrm{~mm} / \mathrm{s}$ ) was also detected, yet with a statistically significant difference ( $p$ value 0.002 , significant) in their ADC values.

The ADC value of osteoblastoma $(0.818 \mathrm{X}$ $10^{-3} \mathrm{~mm} / \mathrm{s}$ ) was within the range of ADC values of the malignant bone marrow lesions.

The ADC values of post therapy neoplastic lesions "metastasis"-1.612 X $10^{-3} \mathrm{~mm} / \mathrm{s}$ and "lymphoma" $1.483 \times 10^{-3} \mathrm{~mm} / \mathrm{s}$ were higher than those 
of prethęrapy malignant lesions (mean, $0.982 \mathrm{X}$ $\left.10^{-3} \mathrm{~mm} / \mathrm{s} ; \mathrm{SD} \pm 0.17 \times 10^{-3} \mathrm{~mm}^{2} / \mathrm{s}\right)$.

Receiver Operating Characteristics (ROC) curve was used to define the best cut off value of ADC $\left(10^{-3} \mathrm{~mm}^{2} / \mathrm{sec}\right)$ between benign and malignant lesions which was $\leq 1.237$, with sensitivity of $100 \%$ specificity of $61.9 \%$ positive predictive value of 66.7 , negative predictive value of $100 \%$ with diagnostic accuracy of $72 \%$.

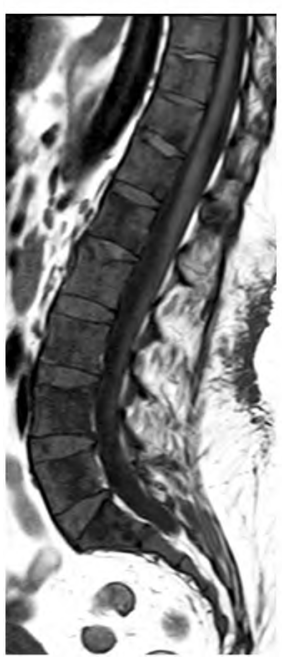

(A)

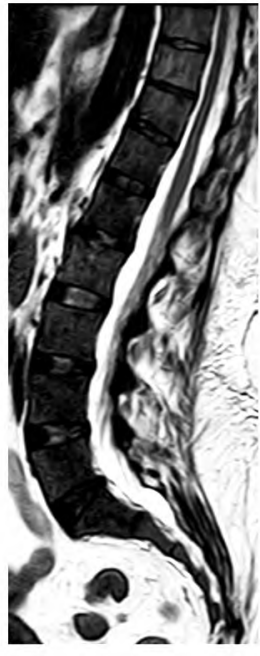

(B)

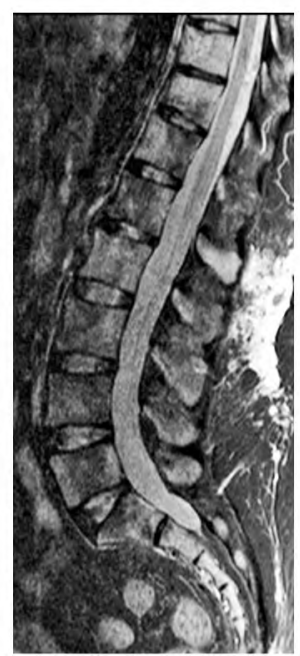

(C)

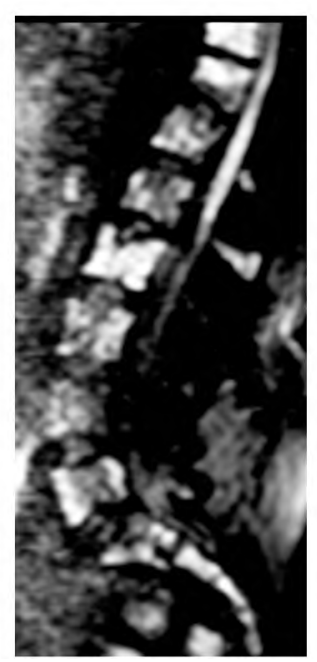

(D)

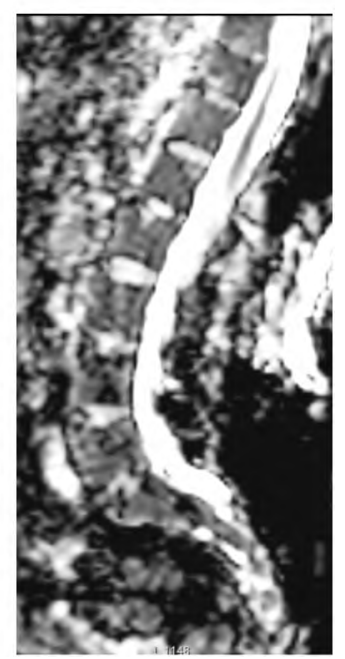

(E)

Fig. (1): 45 year old female known to have breast cancer presenting with back pain. MRI of the lumbosacral spine revealed multiple metastatic deposits: (A) T1, (B) T2, (C) STIR (D) DWI and (E) ADC sagittal images revealing diffuse alteration of the bone marrow signal eliciting low signal on both T1 \& T2 WIs with multiple patchy areas of bright signal intensity on STIR images and patchy areas of restricted diffusion. ADC value: $1.061 \times 10^{-3} \mathrm{~mm} / \mathrm{s}$.

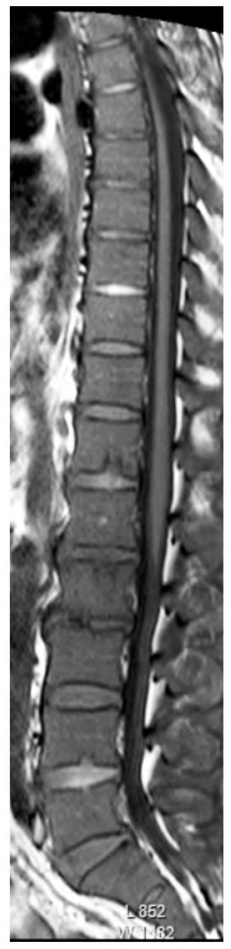

(A)

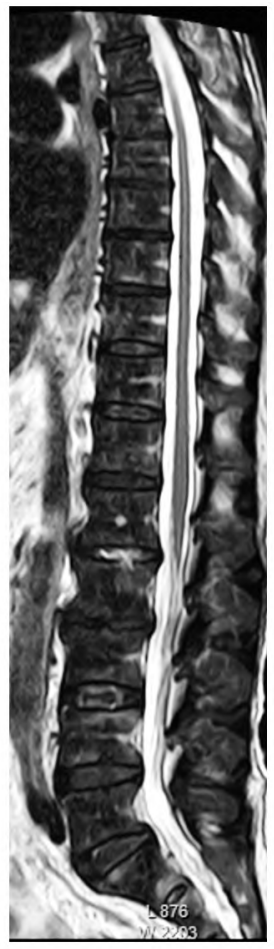

(B)

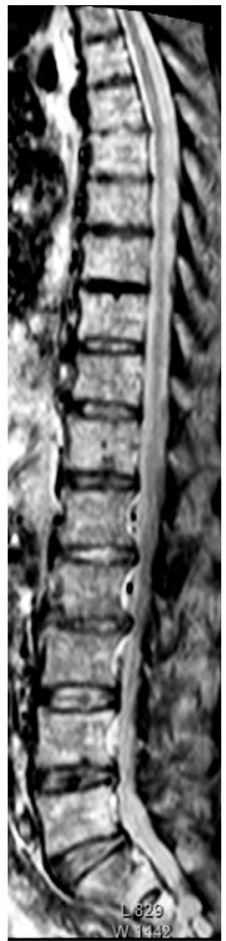

(C)

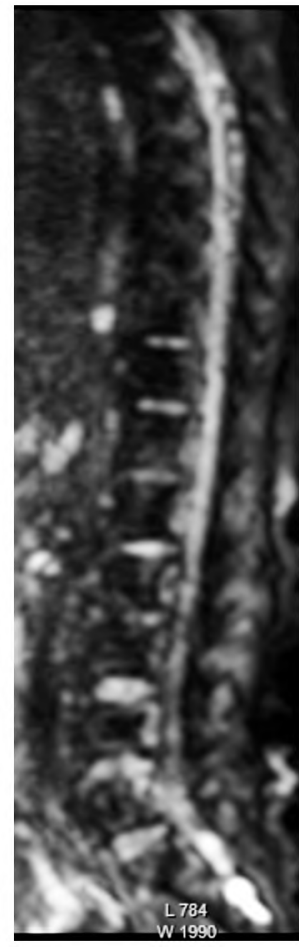

(D)

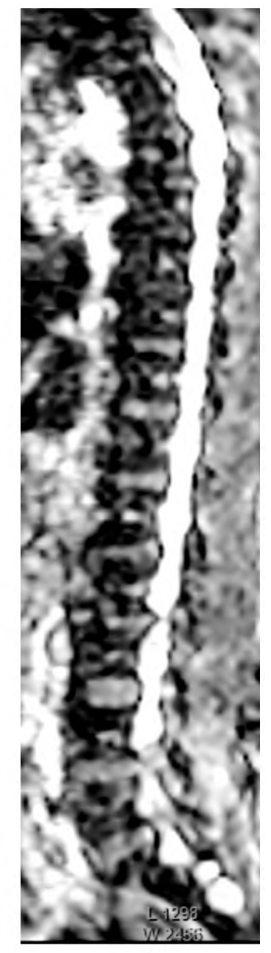

(E)

Fig. (2): 64 year old male known to have multiple myeloma presenting with back pain. MRI of the dorsolumbar spine: (A) T1, (B) T2, (C) STIR (D) DWI and (E) ADC sagittal images of a case of multiple myeloma revealed diffuse alteration of the bone marrow signal of the lumbar vertebrae eliciting low signal on both T1 \& T2 WIs and rather diffuse high signal intensity on STIR images with no areas of restricted diffusion noted. ADC value: $0.975 \times 10^{-3} \mathrm{~mm}^{2} / \mathrm{s}$ 


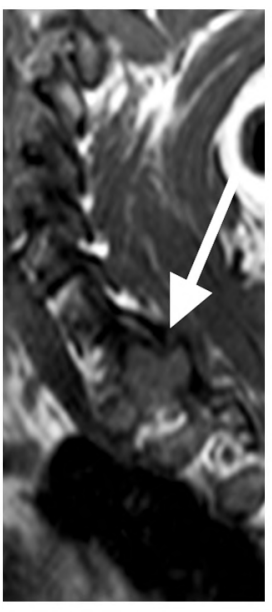

(A)

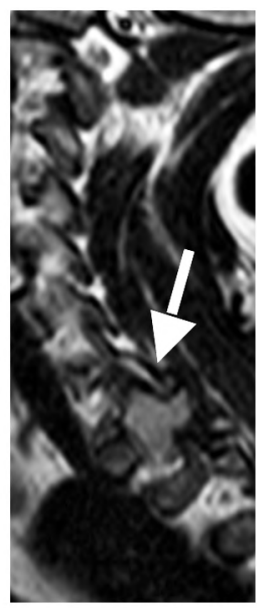

(B)

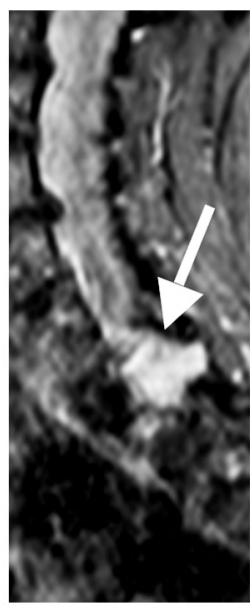

(C)

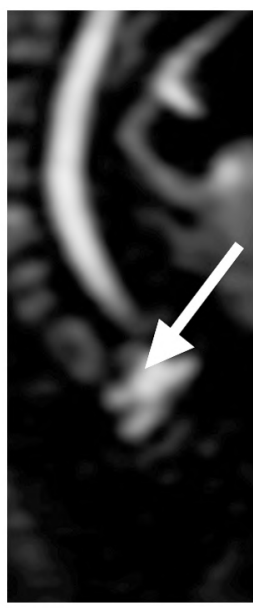

(D)

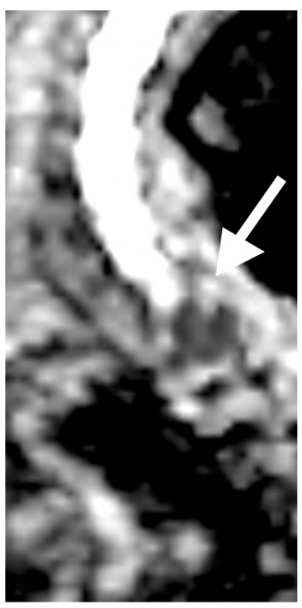

(E)

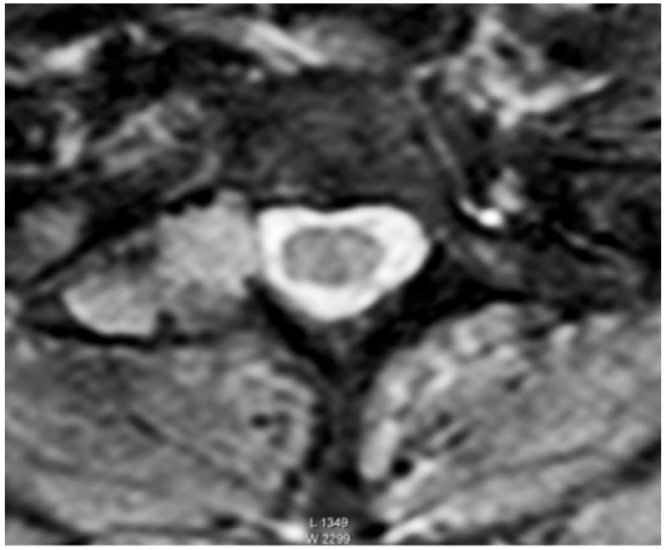

Fig. (3): 39 year old female with neck pain and right upper limb brachialgia. MRI of the cervical spine: (A) T1, (B) T2, (C) STIR, (D) DWI, (E) ADC sagittal images \& (F) axial T2* image of a case of osteoblastoma of D1 right transverse process revealed a well defined lytic expansile lesion of right transverse process of D1. The lesion elicits isointense signal on both T1 \& T2 WIs and bright signal on STIR images with a corressponding area of restricted diffusion. ADC value: 0.818 $\mathrm{X} 10^{-3} \mathrm{~mm} / \mathrm{s}$

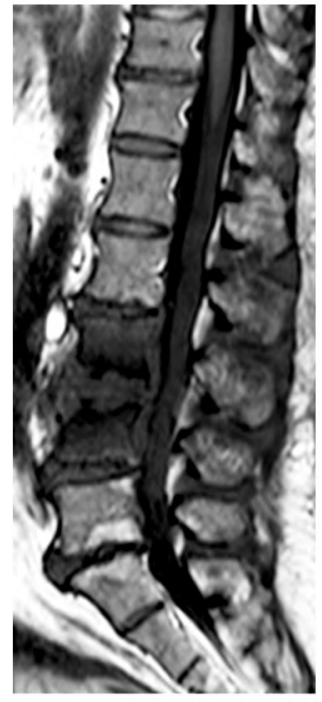

(A)

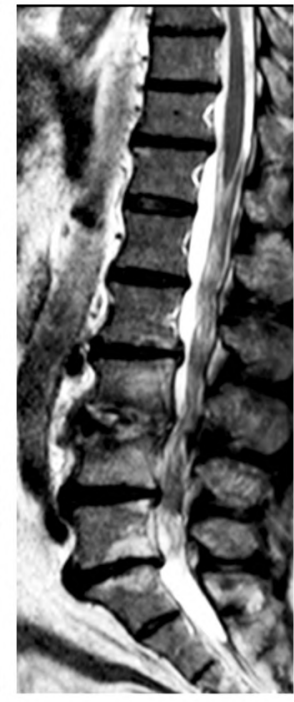

(B)

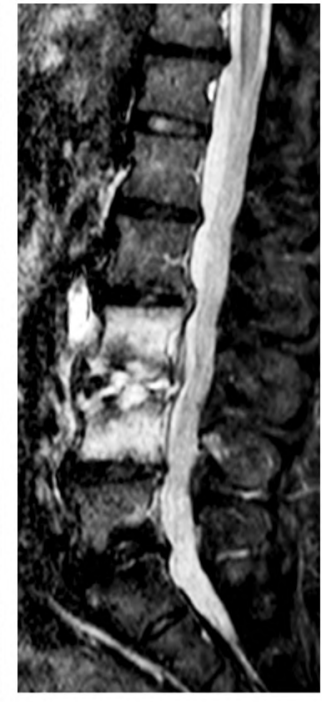

(C)

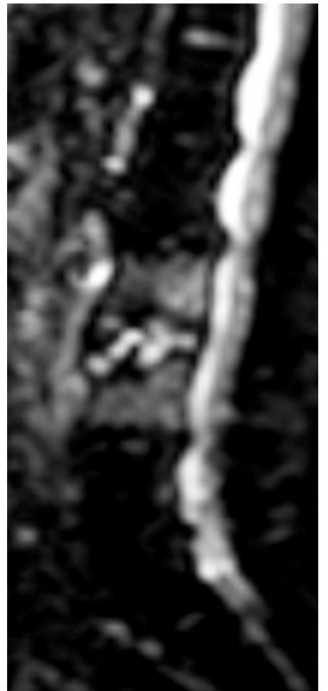

(D)

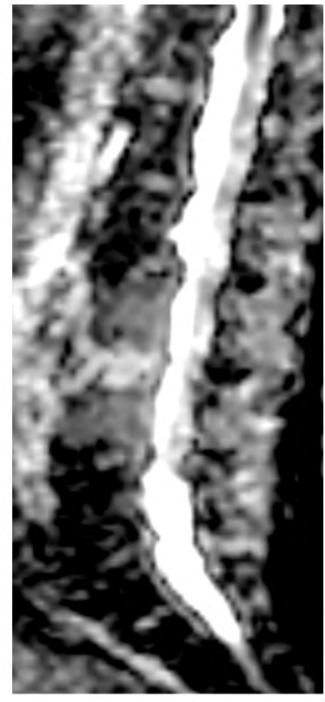

(E)

Fig. (4): 60 year old male "prisoner" presenting with back pain. MRI of the lumbosacral spine: (A) T1, (B) T2, (C) STIR (D) DWI and (E) ADC sagittal images of a case of pyogenic spondylodiscitis. Sagittal T1-weighted image shows diffuse low signal intensity of L3 and L4 vertebrae. Sagittal T2-weighted image and sagittal STIR show corresponding high signal intensity of L3 \& L4 vertebrae as well as the intervening L3/4 disc with diffusion restriction of L3 and L4 vertebrae and intervening disc. ADC value: $1.369 \times 10^{-3} \mathrm{~mm}^{2} / \mathrm{s}$. 


\section{Statistical analysis:}

Data were analyzed using Statistical Program for Social Science (SPSS) Version 20.0. Quantitative data were expressed as mean \pm Standard Deviation (SD). Qualitative data were expressed as frequency and percentage.

\section{The following tests were done:}

- Independent-samples $t$-test of significance was used when comparing between two means.

- Chi-square $\left(\chi^{2}\right)$ test of significance was used in order to compare proportions between two qualitative parameters.

- Receiver Operating Characteristic (ROC curve) analysis was used to find out the overall predictivity of parameter and to find out the best cutoff value with detection of sensitivity and specificity at this cut-off value.

- Probability ( $p$-value).

- $p$-value $<0.05$ was considered significant.

- $p$-value $<0.001$ was considered as highly significant.

- $p$-value $>0.05$ was considered insignificant.

\section{Discussion}

Diffusion weighted MR sequences provide microscopic information to supplement the macroscopic information provided by conventional sequences. It is a non invasive imaging technique which is suitable for probing the physical structure of a biologic tissue at a microscopic level and it exploits the random, translational motion of water protons in a biologic tissue, which reflects the tissue specific diffusion capacity and can be used for tissue characterization.

In this study we found that visual assessment of high signal intensity on high $b$-value (800) was not specific for malignancy because inflammation and hyperactive hematopoietic marrow can result in a similar diffusion restriction, this was in agreement with Zidan et al., [7], Koh et al., [8] and Ballon et al., [9].

On the other hand the quantitative assessment by measuring the $\mathrm{ADC}$ value was able to distinguish benign from malignant high signal intensity on DWI. This was in agreement with Leeds et al., [10], Zhou et al., [11], Padhani et al., [12] \& Zidan et al., [7], who highlighted the necessity of correlating high b-value DW images with corresponding ADC values.
Zidan et al., [7] stated that normal yellow marrow had the lowest ADC value and the infiltrated neoplastic marrow as well as hypercellular red marrow had higher ADC value, on the other hand the infective/inflammatory bone marrow lesion had the highest ADC value.

This was in agreement with our study which revealed that infiltrated neoplastic marrow as well as hypercellular red marrow had higher ADC values while inflammatory lesions and hemangiomas had the highest ADC values.

On the other hand, in agreement with Padhani et al., [12] \& Zidan et al., [7] there was narrow signal intensity and ADC value difference between malignant and red marrow yet, the ADC value difference between the two entities was statistically significant with $p$-value 0.002 .

Our study stated that the mean ADC value of pyogenic vertebral lesions was $1.45 \pm 0.16 \times 10^{-3}$ $\mathrm{mm}^{2} / \mathrm{sec}$ and was significantly higher than that of malignant lesions $\left(0.98 \pm 0.17 \times 10^{-3} \mathrm{~mm}^{2} / \mathrm{sec}\right)(p$ $<0.001)$ with an absence of overlap.

In agreement with our study, Abo Dewan et al., [13] stated that the mean ADC value of pyogenic vertebral lesions was $1.71 \pm 0.12 \times 10^{-3} \mathrm{~mm} / \mathrm{sec}$ and was significantly higher than that of malignant lesions $(0.75 \pm 0.23 \times 10 \mathrm{~mm} / \mathrm{sec})(p=0.007)$ with an absence of overlap. Taskin et al., [14] also stated

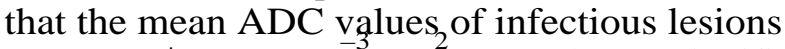
were $1.54 \pm 0.15 \times 10^{-3} \mathrm{~mm}^{2} / \mathrm{sec}$ and were significantly higher than malignant lesions $(p<0.0001)$. Also they reported only 2 of the 23 vertebral infectious lesions displayed ADC values overlapping with malignant lesions.

In contrast to our results Balliu et al., [15] and Fawzy et al., [16] stated that the ADC values of infectious lesions and malignant lesions coincided and therefore they could not differentiate them.

Our study revealed that the mean ADC value of the tuberculous lesions was $1.191 \pm 0.29 \mathrm{X}$ $10^{-3} \mathrm{~mm} / \mathrm{sec}$ with an overlap between tuberculous and malignant lesions, yet with a statistically significant difference with that of malignant lesions $(p=0.034)$.

Abo Dewan et al., [13] study revealed that the mean ADC value of the tuberculous lesions was $0.91 \pm 0.08 \times 10^{-3} \mathrm{~mm} / \mathrm{sec}$ with a non-significant difference with that of malignant lesions $(p=0.143)$ and the presence of an overlap between tuberculous and malignant lesions. Palle et al., [17] also found the mean ADC values of tuberculosis lesions to be 
$1.4 \times 10^{-3} \mathrm{~mm}^{2} / \mathrm{sec}$ and when they took this value as a cutoff in the discrimination of malignant lesions, they found $64.8 \%$ sensitivity, $75 \%$ specificity, and $74.5 \%$ positive predictive values. However, due to the fact that this ADC value displays values overlapping with the ADC values of metastatic vertebral lesions, they emphasized that the ADC values should be evaluated with the clinical history and routine MR findings. These results were quite similar to ours, but there were some limitations in this comparison since the number of tuberculous lesions in our study was small compared to Palle et al., [17].

Our study detected that DWIs can differentiate between atypical hemangioma and metastatic spine lesions. We found atypical and typical hemangiomas in our study expressing non restricted diffusion in the form of low signal on DWI, while the metastases showed restricted diffusion in the form of high signal in DWI and low signal in ADC maps. We found significantly low ADC values calculated in metastatic bony lesions compared with typical and atypical hemangioma. These differences were grossly apparent. In our results the mean ADC value of hemangiomas was found as $1.406 \mathrm{X}$ $10^{-3} \mathrm{~mm}^{2} / \mathrm{sec}$. The mean ADC value of metastatic bony lesions was found as $0.982 \times 10^{-3} \mathrm{~mm}^{2} / \mathrm{sec}$.

This was in agreement with Matrawy et al., [18] that stated that restricted diffusion was seen in metastasis while in hemangioma it shows no restriction, the mean $\mathrm{ADC}_{-3}$ valuę of hemangiomas was found as $1.54 \times 10^{-3} \mathrm{~mm}^{2} / \mathrm{sec}$ and the mean $\mathrm{ADC}$ value of metaștatic bony lesions was found as $0.83 \times 10^{-3} \mathrm{~mm}^{2} / \mathrm{sec}$. Taskin et al., [14] also found that ADC values for atypical hemangiomas were between 1.94 and $2.82 \times 10^{-3} \mathrm{~mm}_{-3}^{2} / \mathrm{sec}$. With a mean ADC value of $1.80 \pm 0.37 \times 10^{-3} \mathrm{~mm}^{2} / \mathrm{sec}$, while the ADC values of malignant lesions were between 0.43 and $1.44 \times 10^{-3} \mathrm{~mm}_{-3}^{2} / \mathrm{s} e ̨ c$ with a mean $\mathrm{ADC}$ value of $0.94 \pm 0.34 \times 10^{-3} \mathrm{~mm} / \mathrm{sec}$. Also our results are in agreement with (Leeds et al., [10]) who reported that hemangiomas had ADC values higher than those of metastases because of the contribution of water molecules within the vascular spaces.

(Byun et al., [19]) have investigated the usefulness of DWI for the assessment of response to therapy. Affected vertebrae appeared hyperintense on DWI images prior to therapy. Interestingly, for patients who experienced clinical improvement, diseased vertebrae were hypointense to normal bone marrow on follow-up diffusion images acquired one month after therapy.
In this study two cases of malignant lesions under therapy were of hyperintense signal on DWIs, yet showing higher ADC values 1.612 and 1.483 $\mathrm{X} 10^{-3} \mathrm{~mm} / \mathrm{sec}$ compared to range ${ }_{-3}$ of untreated malignant cases $\left(0.624-1.237 \times 10^{-3} \mathrm{~mm} / \mathrm{sec}\right)$.

This was in agreement with Khoo et al., [1] that stated that when bone marrow disease is treated successfully, the tumour cell death results in increased water diffusivity manifested as increased ADC values, yet there is some limitations in our study since the number of treated lesions in our study was small.

In the present study we rescorderd that the best cut off value of ADC $\left(10^{-3} \mathrm{~mm}^{2} / \mathrm{sec}\right)$ between benign and malignant lesions was $\leq 1.237$, with sensitivity of $100 \%$ specificity of $61.9 \%$ positive predictive value of $66.7 \%$, negative predictive value of $100 \%$ with diagnostic accuracy of $72 \%$. Other studies also defined an ADC threshold (X $10^{-3} \mathrm{~mm} / \mathrm{sec}$ ) for differentiating benign from malignant lesions; Fawzy et al., [16] recorded cut off value of $\mathrm{ADC}<1.15$, Wonglaksanapimon et al., $[20]<0.89$, Ta skin et al., [14] $<1.32$, Sung et al., [21]<1.242, Geith et a.1, [22] <1.70, Abo Dewan et al., [13] $<1.21 \&$ Yehya et al., [23] $<0.78$.

Dallaudière et al., [3] stated that ADC values could also differentiate between axial active inflammatory lesions and degenerative end plate changes; mean ADC values were significantly different between axial active inflammatory lesions and degenerative changes $(p=0.0005)$, best ADC cut-off value was $0.58 \times 10^{-3} \mathrm{~mm} / \mathrm{sec}$, this was in agreement with our study which shows highly significant statistical difference ( $p$-value $<0.001)$ between causes of vertebral end plate abnormalities (degenerative and inflammatory) according to ADC with cut off value of ADC $0.664 \times 10^{-3} \mathrm{~mm} / \mathrm{sec}$.

Eguchi et al., [6] also agreed with our study and showed hyperintensity of vertebral bone marrow on DWIs in all patients with spinal infections, but not in any patients with degenerative changes. Mean ADC values for infectious bone marrow were significantly higher than for normal and degenerative bone marrow.

\section{Conclusion:}

Diffusion weighted MRI is a reliable tool in characterization of different vertebral bone marrow abnormalities. The routine MRI protocol of spine examinations could be modified to include DWI as a cost effective substitute for the gadolinium enhanced scan especially in patients with contraindication for contrast administration. 


\section{References}

1- KHOO M.M., TYLER P.A. and SAIFUDDIN A.: Diffusion-Weighted Imaging (DWI) in musculoskeletal MRI: A critical review. Skeletal Radiology; 40: 665-81, 2011.

2- KHEDR S.A., HASSAAN M.A., ABDELRAZEK N.M., et al.: Diagnostic impact of echo planar diffusion-weighted magnetic resonance imaging (DWI) in musculoskeletal neoplastic masses using Apparent Diffusion Coefficient (ADC) mapping as a quantitative assessment tool. Journal of Radiology and Nuclear Medicine; 43: 219-26, 2012.

3- DALLAUDIÈRE B., DAUTRY R., PREUX P., PEROZZIELLO A., LINCOT J., SCHOUMAN-CLAEYS A. and SERFATY J.: Comparison of apparent diffusion coefficient in spondylarthritis axial active inflammatory lesions and type 1 modic changes. European Journal of Radiology; 83: 366-70, 2014.

4- PUI M.H., MITHA A., RAE W.I. and CORR P.: Diffusionweighted magnetic resonance imaging of spinal infection and malignancy. J. Neuroimaging; 15: 164-70, 2005.

5- DIETRICH O., GEITH T., REISER M.F. and BAURMELNYK A.: Diffusion imaging of the vertebral bone marrow. NMR Biomed, 2015.

6- EGUCHI Y., OHTORI S., YAMASHITA M., YAMAUCHI K., SUZUKI M., ORITA S., KAMODA H., ARAI G., ISHIKAWA T., MIYAGI M., OCHIAI N., KISHIDA S., MASUDA Y., OCHI S., KIKAWA T., TAKASO M., AOKI Y., INOUE G., TOYONE T. and TAKAHASHI K.: Diffusion magnetic resonance imaging to differentiate degenerative from infectious endplate abnormalities in the lumbar spine. Spine; 36: 198-202, 2011.

7- ZIDAN D.Z. and ELGHAZALY H.A.: Can unenhanced multiparametric MRI substitute gadolinium-enhanced MRI in the characterization of vertebral marrow infiltrative lesions. The Egyptian Journal of Radiology and Nuclear Medicine, 2014.

8- KOH D. and COLLINS D.: Diffusion-Weighted MRI in the Body: Applications and Challenges in Oncology. A.J.R.; 188: 1622-35, 2007.

9- BALLON D., WATTS R., DYKE J.P., et al.: Imaging therapeutic response in human bone marrow using rapid whole-body MRI. Magn. Reson. Med.; 52: 1234-8, 2004.

10-LEEDS N.E., KUMAR A.J., ZHOU X.J. and McKINNON G.C.: Magnetic Resonance Imaging of Benign Spinal Lesions Simulating Metastasis: Role of DiffusionWeighted Imaging. Topics in Magnetic Resonance Imaging; 11 (4): 224-34, 2000.

11- ZHOU X.J., LEEDS N.E., McKINNON G.C. and KUMAR A.J.: Characterization of benign and metastatic vertebral compression fractures with quantitative diffusion MR imaging. Am. J. Neuroradiol.; 23: 165-70, 2002.

12- PADHANI A., KOH D.M. and COLLINS D.: Wholebody diffusion-weighted MR imaging in cancer: Current status and research directions. Radiology; 261: 3, 2011.

13- ABO DEWAN K.A.W., SALAMA A.A., EL HABASHY H.M.S. and KHALIL A.E.S.: Evaluation of benign and malignant vertebral lesions with diffusion weighted mag- netic resonance imaging and apparent diffusion coefficient measurements. Egypt. J. Radiol. Nucl. Med.; 46: 423-33, 2015.

14- TAŞKIN G., iNCESU K. and ASLAN K.: The value of apparent diffusion coefficient measurements in the differential diagnosis of vertebral bone marrow lesions. Turk. J. Med. Sci.; 43: 379-87, 2013.

15- BALLIU E., VILANOVA J.C., PELAEZ I., PUIG J., REMOLLO S., BARCELO C., BARCELO J. and PEDRAZA S.: Diagnostic value of apparent diffusion coefficients to differentiate benign from malignant vertebral bone marrow lesions. Eur. J. Radiol.; 69: 560-6, 2009.

16- FAWZY F., TANTAWY H.I., RAGHEB A. and ABO HASHEM S.: Diagnostic value of apparent diffusion coefficient to differentiate benign from malignant vertebral bone marrow lesions. The Egyptian Journal of Radiology and Nuclear Medicine; 44: 265-71, 2013.

17- PALLE L., REDDY M.B. and REDDY K.J.: Role of magnetic resonance diffusion imaging and apparent diffusion coefficient values in the evaluation of spinal tuberculosis in Indian patients. Indian J. Radiol. Imaging; 20: 279-83, 2010.

18- MATRAWY K.A., EL-NEKEIDY A. and EL-SHERIDY H.G.: Atypical hemangioma and malignant lesions of spine: Can diffusion weighted Magnetic Resonance Imaging help to differentiate. The Egyptian Journal of Radiology and Nuclear Medicine; 44: 259-63, 2013.

19- BYUN W.M., SHIN S.O., CHANG Y., LEE S.J., FINSTERBUSCH J. and FRAHM J.: Diffusion-weighted MR imaging of metastatic disease of the spine: Assessment of response to therapy. Am. J. Neuroradiol.; 23: 906-12, 2002.

20- WONGLAKSANAPIMON S., CHAWALPARIT O., KHUMPUNNIP S., TRITRAKARN S.O., CHIEWVIT P. and CHARNCHAOWANISH P.: Vertebral body compression fracture: Discriminating benign from malignant causes by diffusionweighted MR imaging and apparent diffusion coefficient value. J. Med. Assoc. Thai.; 95: 817, 2012.

21- SUNG J.K., JEE W.H., JUNG J.Y., CHOI M., LEE S.Y., KIM Y.H., HA K.Y. and PARK C.K.: Differentiation of acute osteoporotic and malignant compression fractures of the spine: Use of additive qualitative and quantitative axial diffusion-weighted MR imaging to conventional MR imaging at 3.0 T. Radiology; 271: 488-98, 2014.

22- GEITH T., SCHMIDT G., BIFFAR A., DIETRICH O., DUERR H.R., REISER M. and BAUR-MELNYK A.: Quantitative evaluation of benign and malignant vertebral fractures with diffusion-weighted MRI: what is the optimum combination of $b$-values for ADC-based lesion differentiation with the single-shot turbo spin-echo sequence? Am. J. Roentgenol.; 203: 582-8, 2014.

23- YEHYA A., EL-SHEIKH M., BARAKAT M.S. and ABD ELSALAM M.: Collapsed Vertebrae: New Diagnostic Modality for Better Management. Egyptian Journal of Neurosurgery; 29 (3): 59-66, 2014. 


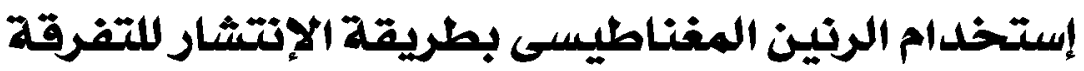

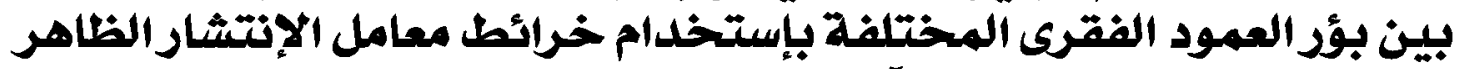 كآداة للتقييم الستحمى}

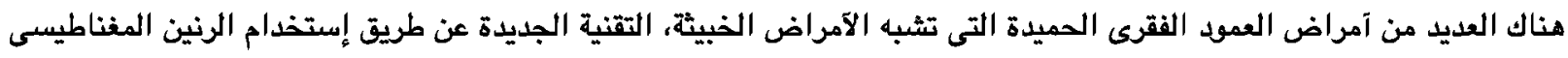

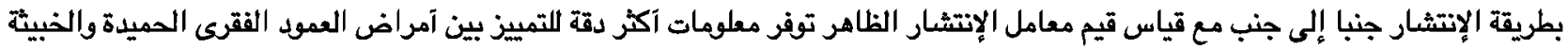

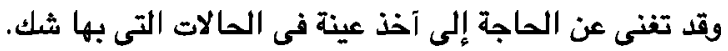

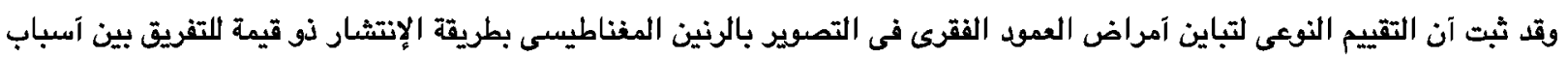

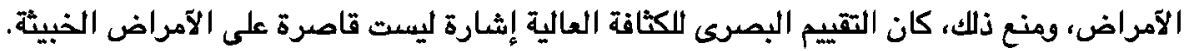

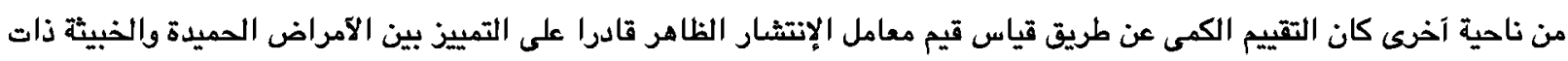
الكثافة العالية في الرنين المغناطيسي بطريقة التقين الإنتشار.

فى دراستنا، سجلت الآقرام وكذلك النخاع الآحمر مفرط الخلوية قيم آعلى من النخاع الآصفر الطبيعى. وبجلت الآمراض الإلتهابية والوحمات

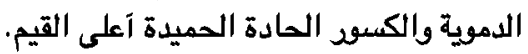

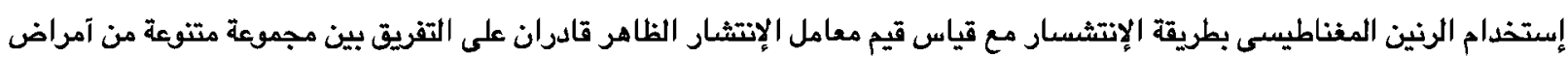

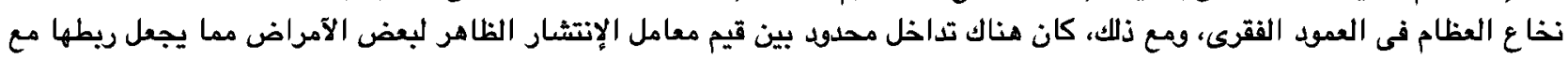

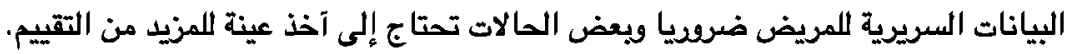

